\title{
Concrete Cloth: An Innovative Versatile Construction Material
}

\author{
Bharat Bhushan Jindal* \\ Department of Civil Engineering, Maharishi Markandeshwar University, Ambala, Haryana, India
}

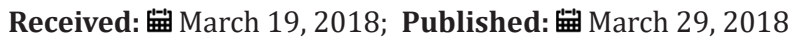

*Corresponding author: Bharat Bhushan Jindal, Department of Civil Engineering, Maharishi Markandeshwar University, India, Tel: +91-7589389247; Email: bbjal1972@hotmail.com

\begin{abstract}
Concrete as a construction material is recognized globally but the inquest to improve its flexibility has always attracted the attention of researchers. The increasing cost of repair work due to weathering actions, ground surface damage, seepage in water canals always remained a concern. This paper focuses on to explore the manufacturing process as well as the use of Concrete canvas or Concrete cloth in the construction sector. It's being a ceramic material; Concrete Canvas may find its tremendous scope in the construction sector as a fire resistance and waterproofing material.
\end{abstract}

Keywords: Concrete cloth; Concrete canvas; Flexibility; Shelter

\section{Introduction}

Concrete is a globally recognized as a construction material possessing a versatility of mechanical properties such as good load taking capacity, customizable compressive strength, good impermeability and better durability. Moreover, concrete may be moulded into a required shape which revolutionized the construction industry. The major issue which is always of concern was concrete's poor ability to resist tensile stresses. Concrete loses its flexibility, while it is hardened. For making the concrete flexible the design philosophy adopted in conventional concrete need to be altered.

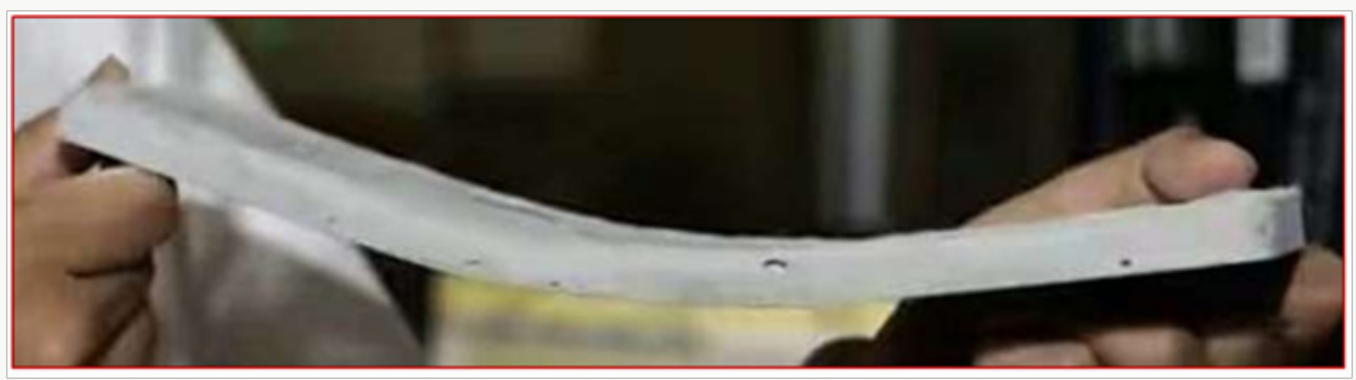

Figure 1: Flexible concrete specimen made by Professor Victor Li.

To overcome the flexibility issue Professor Victor Li at the University of Michigan developed a new material consisting of a special type of materials which makes it flexible and named it as Engineered Cementitious Composite (ECC) as shown in Figure 1. British Engineering Company introduced a new material referred as Concrete Canvas or concrete cloth (CC). This material possesses flexibility in comparison to conventional concrete. In the flexible concrete, the coarse aggregates are eliminated.

The concrete cloth has a vast scope of application such as in slope protection construction, mining, overlaying on underground pipelines, agriculture, Military application and much more. The primarily concrete cloth was invented for urgent applications for construction of shelters.

The typical concrete cloth consists of a three-dimensional fiber matrix, containing a dry concrete mix with backing by PVC on one surface of the cloth to make it waterproof [1]. Hydrophilic fibers on the other surface support the hydration by drawing water into the cement. The canvas material can be hydrated by spraying or by kept immersed in water. A typical sectional view of the concrete canvas is shown in Figure 2a-b. 


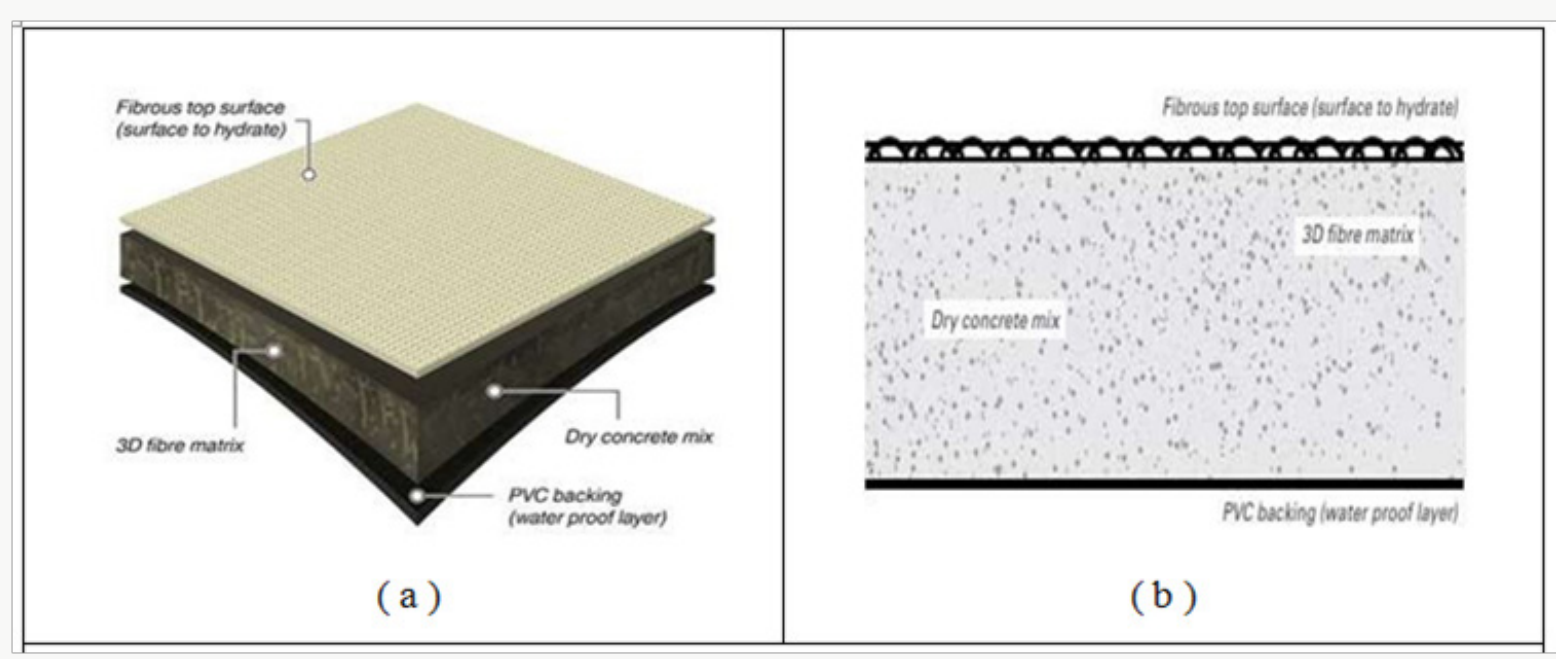

Figure 2: (a) Concrete canvas, (b) Sectional view of CC.

Concrete Cloth (CC) has a completely different preparation process in comparison to conventional 3D spacer fabric reinforced cementitious composites. Before setting of the cement powder on the surface, concrete cloth which is a flexible 3D spacer fabric impregnated with cement powder can be placed like a soft cloth. Water can be sprayed afterward on the top surface of cloth for hydration requirement. On getting hardened, a thin composite layer, that is flexible and durable, water-resistant and fire-resistant, forms and covers the structure or element, whatever be its shape [2].

Thus concrete cloth can be quickly and effortlessly nailed, stapled through or covered with a good quality adhesive for efficient connectivity with the surface. The concrete cloth was efficiently used as a structural element to cover prefabricated shelters, the pathway for vehicles or pedestrians and unlimited applications. Once set, this cloth covers the concrete, prevent the crack propagation \& imparting a secure plastic failure mode [2]. The preparation of concrete cloth may also hamper the effective hydration process by shielding the cement powder from water, affecting the mechanical properties of hardened cloth.

\section{Preparation of Concrete Cloth/Canvas}

\section{Raw materials}

Dry concrete mixture: Dry concrete mixture for concrete canvas is generally prepared by selecting dry cement powder which has to provide both high mechanical strengths and short setting times. Calcium aluminate cement (CAC), Calcium sulfoaluminate cement (CSA) or combination of both are taken as per the practical application of CC. Calcium sulfoaluminate cement is a very suitable binder for concrete cloth due to its better mechanical strength, resistance to corrosion, low porosity, higher resistance to weathering actions, low $\mathrm{pH}$, better dimensional stability and good setting property [2-4].

Fiber matrix: A three-dimensional fiber matrix, as shown in Figure 3 forms a reinforcing matrix within the Concrete Cloth. On any external impact, the reinforcing property of fibers helps in absorbing the impact energy, and help to maintain the structural integrity of the concrete. The fiber matrix reinforces the concrete, preventing crack propagation \& providing a safe plastic failure mode.

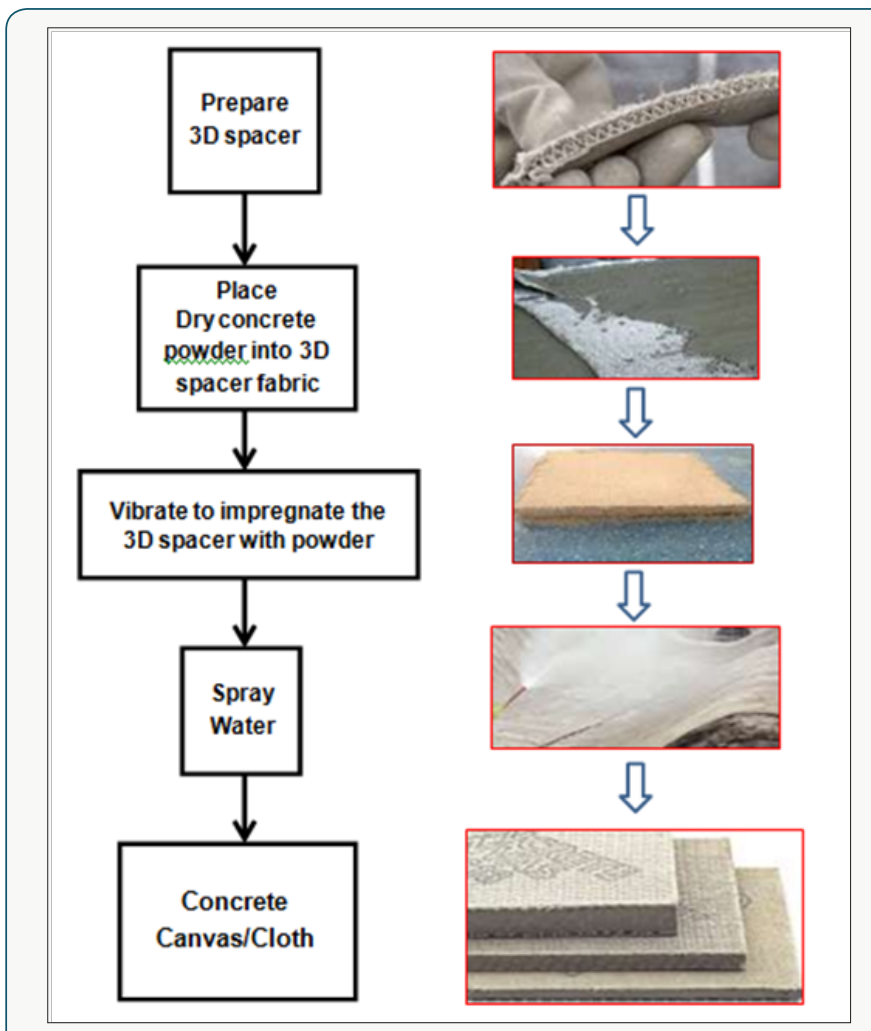

Figure 3: Preaparation flow chart of Concrete Canvas/ Cloth.

Membranes: An impermeable PVC membrane on one side for making CC waterproof against any attack by moisture or water from the surrounding. A hydrophilic fibers (Polyethylene and Polypropylene yarns) membrane is attached to the opposite surface to PVC membrane which helps in hydration process and is used for drawing water into the aggregate $[2,5,6]$. 


\section{Preparation Flow Chart of Concrete Canvas/Cloth (CC)}

A flow chart illustrating the various steps used in the preparation of concrete canvas is shown in Figure 3.

\section{Applications in Civil Engineering}

\section{Slope protection}

Concrete canvas can be very effectively used for laying on the slopes of dams, roads, embankments to protect it from soil erosion, reduction of shear strength caused by many factors and to reduce the maintenance cost of protection. Slope protection is shown in Figure 4(a).

\section{Ditch lining}

Ditches are lined with concrete cloth to protects the seepage of water flowing into the ditch. Concrete can be effectively and economically be used because the cost of installation is very less as well as less time- consuming in comparison to conventional methods of the lining. Concrete cloth application in ditch lining is shown in Figure 4(b).

\section{Pipeline protection}

Concrete cloth can be used as a protective cover against corrosion and leakage in underground pipes as shown in Figure 4(c). It provides a superior tough shield to resist the water pressure in case of pipes used for water transmission.

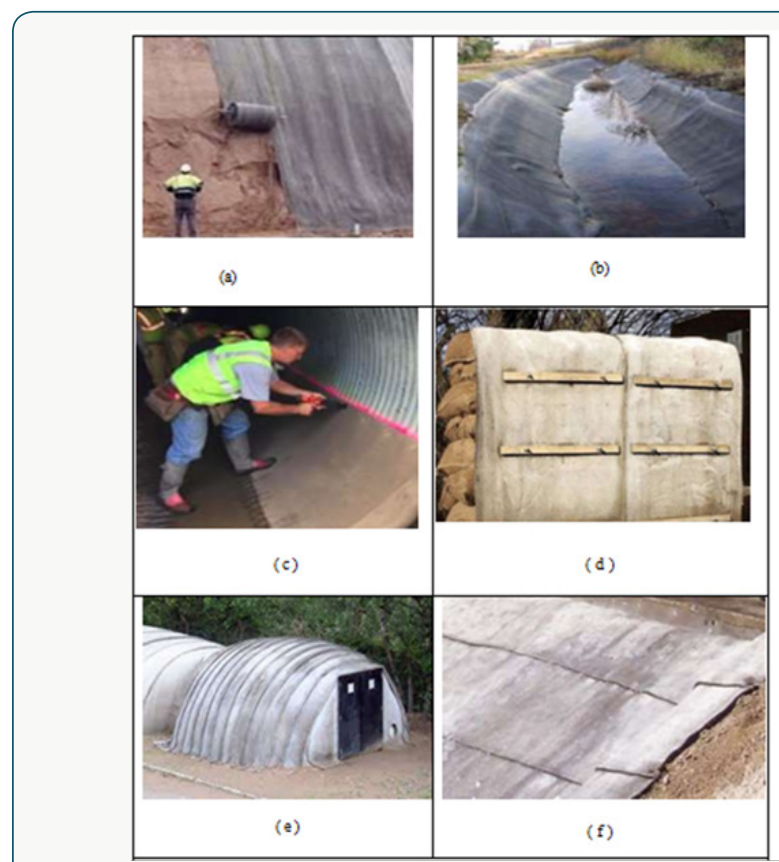

Figure 4: Concrete cloth use as (a) slope protection, (b) ditch lining, (c) pipeline protection, (d) sandbags replacement, (e) shelters, (f) ground resurfacing.

\section{Mining applications}

Concrete cloth can be used instead of spraying concrete to protect the inner surface of the mines. The replacement of sprayed concrete may reduce the cost up to $20 \%$ with the use of concrete cloth.

\section{Dust suspension application at helipads}

Concrete cloth can be used as a dust suspension at helipad where dust get suspended due to the turbulence created in the air by the helicopter's rotator.

\section{Sandbag reinforcement}

British Army uses a concrete cloth to strengthen sandbags which were used as a wall to safeguard from sustained incoming fire, outgoing muzzle fly ash, and environmental exposure. A sandbag wall protected by concrete cloth as shown in Figure 4 (d), can withstand 900 rounds of 7.62 NATO, fired by a GPMG LR at a range of $100 \mathrm{~m}$.

\section{Deployable shelters}

Concrete canvas due can be used as a thin-walled concrete shelter for robust and lightweight deployability of hardened shelters that required only water and air for construction. The concrete canvas use as a shelter is as the one shown in Figure 4(e). Concrete Canvas Shelters provide much better environmental protection, increased security, saving effort and cost in long term as compared to conventional tent shelters.

\section{Ground resurfacing}

Concrete Cloth can be secured with ground anchors to effortlessly create a concrete surface for flooring, pedestrian walkways and resurfacing quickly the worn out surfaces as shown in Figure 4a-f.

\section{Advantages of Concrete Canvas/Cloth}

a. The concrete Cloth is easy to carry, transport and installed without specialized equipment. Concrete cloth layers can be cut to the desired length using basic hand tools eliminating the hazards associated with using power tools in high-risk environments. It can be hydrated with less effort by spraying or being fully immersed in water.

b. It hardens and gains nearly $80 \%$ of strength within 24 hours. Even the hardening time can further be reduced by using some accelerators in the dry concrete mixture.

c. It is very flexible in use, can be tailored using simple tools and easily repairable.

d. It absorbs external impacts due to inherent fiber reinforcement and shows better structural stability.

e. The concrete cloth is highly resistant to acid attacks as well as ultraviolet waves. It cannot catch fire because of a ceramic-based material.

f. The PVC backing makes it waterproof. 


\section{Commercial Availability}

Concrete canvas is presently available in three variants based upon thickness. These variants vary in thickness, types of their application, properties, and composition are CC5, CC8, CC13 of 5, 8 and $13 \mathrm{~mm}$ thickness. It is available wrapped in bulk rolls packed in bags which make it very convenient to transport and easy for laying at the site. It requires minimum labor as well very economical for application along with high performance and durability [7-10].

\section{Conclusion}

The concrete cloth is the latest of flexible concretes in the construction sector. Concrete canvas owing to its easy manufacturing process, better flexibility properties, a higher degree of waterproofing and easy to customized use can prove a boon for the construction industry. It can be helpful in both temporary and well as permanent purpose. It is made of ceramic material which expands its utilization in the fire resistance purposes.

\section{References}

1. M Akhtar, RS Dangi (2015) Study of Canvas Concrete in Civil Engineering Works. International Journal for Scientific Research \& Development $3(1)$.
2. F Han, $\mathrm{H}$ Chen, X Li, B Bao, T Lv, et al. (2016) Improvement of mechanical properties of concrete canvas by anhydrite-modified calcium sulfoaluminate cement. Journal of Composite Materials 50(14): 19371950.

3. IA Chen, MC Juenger (2011) Synthesis and hydration of calcium sulfoaluminate-belite cements with varied phase compositions. Journal of Materials Science 46(8): 2568-2577.

4. D Gastaldi, F Canonico, E Boccaleri (2009) Ettringite and calcium sulfoaluminate cement: investigation of water content by near-infrared spectroscopy. Journal of materials science 44(21): 5788-5794.

5. G Anjaneyulu (2017) Study Of Concrete Cloth (Cc) In Civil Engineering Constructions Works.

6. www.concretecanvas.co.uk.

7. http://www.a2z4home.com/concrete-cement-products/

8. www.exploratorium.edu/publicspaces/blog/concrete-canvas

9. https://www.nbmcw.com/concrete/28977

10. http://alfreih.com.sa/concrete-canvas/

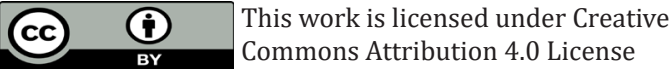

To Submit Your Article Click Here:

Submit Article

DOI: 10.32474/TCEIA.2018.01.000123

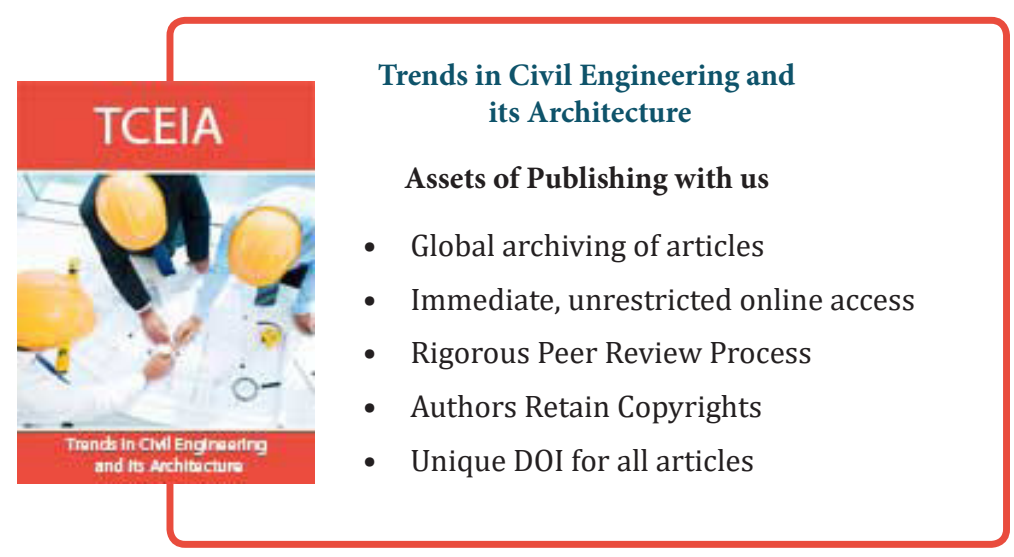

